\title{
MATERIAL UNACCOUNTED FOR AT THE SOUTHWEST EXPERIMENTAL FAST OXIDE REACTOR: THE SEFOR MUF
}

WILLIAM A. HIGINBOTHAM

\author{
NOVEMBER 7, 1994 \\ DEPARTMENT OF ADVANCED TECHNOLOGY \\ Brookhaven National Laboratory \\ Associated Universities, Inc. \\ Upton, Long Island, New York 11973 \\ Under Contract No. DE-ACO2-76CH00016 with the \\ UNITED STATES DEPARTMENT OF ENERGY
} DEPARTMENT OF ADVANCED TECHNOLOGY $Y$ W Brookhaven National Laboratory Building 197C 
$\mathrm{BNL}-52443$

FORMAL

\title{
MATERIAL UNACCOUNTED FOR AT THE SOUTHWEST EXPERIMENTAL FAST OXIDE REACTOR: THE SEFOR MUF
}

\author{
WILLIAM A. HIGINBOTHAM
}

NOVEMBER 7, 1994

\section{DISCLAIMER}

This report was prepared as an account of work sponsored by an agency of the United States Government. Neither the United States Government nor any agency thereof, nor any of their employees, makes any warranty, express or implied, or assumes any legal liability or responsibility for the accuracy, completeness, or usefulness of any information, apparatus, product, or process disclosed, or represents that its use would not infringe privately owned rights. Reference herein to any specific commercial product, process, or service by trade name, trademark, manufacturer, or otherwise does not necessarily constitute or imply its endorsement, recommendation, or favoring by the United States Government or any agency thereof. The views and opinions of authors expressed herein do not necessarily state or reflect those of the United States Government or any agency thereof.

\section{DEPARTMENT OF ADVANCED TECHOLOGY \\ Brookhaven National Laboratory \\ Associated Universities, Inc. Upton, Long Island, New York 11973}

Under Contract No. DE-ACO2-76CH00016 with the UNITED STATES DEPARTMENT OF ENERGY 


\section{DISCLAIMER}

This report was prepared as an account of work sponsored by an agency of the United States Government. Neither the United states Government nor any agency thereof, nor any of their employees, not any of their contractors, subcontractors, or their employees, makes any warranty, express or implied, or assumes any legal liability or responsibility for the accuracy, completeness, or usefulness of any information, apparatus, product, or process disclosed, or represents that its use would not infringe privately owned rights. Reference herein to any specific commercial product, process, or service by trade name, trademark, manufacturer, or otherwise, does not necessarily constitute or imply its endorsement, recommendation, or favoring by the United states Government or any agency, contractor, or subcontractor thereof. The views and opinions of authors expressed herein do not necessarily state or reflect those of the United states Government or any agency, contractor or subcontractor thereof. 


\section{Abstract}

The U.S. Atomic Energy Commission contracted with the General Electric Company to design, construct, and operate the Southwest Experimental Fast oxide Reactor (SEFOR) to measure the Doppler effect for fast neutron breeder reactors. It contracted with Nuclear Fuel services to fabricate the fuel rods for the reactor. When the reactor went critical in May, 1969, it appeared that some of the mixed uranium-plutonium oxide (MOX) fuel rods did not contain the specified quantity of plutonium. The SEFOR operators soon found several fuel rods which appeared to be low in plutonium. The safeguards group at Brookhaven was asked to look into the problem and, if possible, determine how much plutonium was missing from the unirradiated rods and from the larger number which had been slightly irradiated in the reactor. It was decided that the plutonium content of the unirradiated and irradiated rods could be measured relative to a reference rod using a high resolution gammaray detector and also by neutron measurements using an autocorrelation circuit recently developed at the Naval Research Laboratory (NRL). During the next two years, Brookhaven personnel and $C$. V. Strain of NRL made several trips to the SEFOR reactor. About 250 of the 775 rods were measured by two or more methods, using a sodium-iodide detector, a high-resolution germanium detector, a neutron detector, or the reactor (to measure reactivity). We concluded that $4.6 \pm 0.46 \mathrm{~kg}$ of plutonium was missing out of the $433 \mathrm{~kg}$ that the rods should have contained. This report describes the SEFOR experiment and the procedures used to determine the material unaccounted for, or MUF. 


\section{Table of Contents}

Page No.

Abstract

iii

Table of Contents

iv

List of Figures

$\mathrm{v}$

1.0 Introduction 1

2.0 Preliminary Measurements 2

3.0 The August 1969 Campaign 4

4.0 The Response To The First Report 6

5.0 The June 1970 Measurements 7

6.0 Additional Experiments \& Data Analysis 7

7.0 The Final Report 8

8.0 Conclusions 9

9.0 Acknowledgments 11

10.0 Appendices 12

11.0 References 18 


\section{List of Figures}

Page No.

Figure 1

Fuel Rod (from Ref. 7)

20

vi 


\begin{abstract}
MATERIAL UNACCOUNTED FOR AT THE SOUTHWEST EXPERIMENTAL FAST OXIDE REACTOR: THE SEFOR MUF

W. A. Higinbotham
\end{abstract}

\title{
1.0 INTRODUCTION
}

The Southwest Experimental Fast oxide Reactor (SEFOR) was constructed for the US Atomic Energy Commission (AEC) to measure the Doppler effect on reactivity, which occurs when the fuel is heated to high temperatures. The experiment determined how effective the Doppler effect would be in ensuring the safety of such reactors.

The AEC contracted with the General Electric Co. (GE) to design and operate the reactor, and with Nuclear Fuel services (NFS) to fabricate the fuel rods. The AEC supplied $545 \mathrm{~kg}$ of plutonium to NFS, in the form of plutonium nitrate solution, from its Hanford Nuclear Facility, then operated by the Atlantic Richfield Hanford Co. (ARHCO), near Richland, WA.

In addition to General Electric (which had the main responsibility for designing, constructing, and operating the reactor), the participants in the project were the AEC, the Kernforschungszentrum Karlsruhe (KFK), Euratom, and southwest Atomic Energy Associates, a consortium of seventeen utilities in the southwestern part of the United States.

The SEFOR reactor was constructed about 20 miles south of Fayetteville, Ark. during 1965-68. Things went fast in those days. A group at GE under Karl Cohen designed the LMFBR and checked its calculations with critical experiments. In May, 1969, the reactor was completed and fuel loading began. From its design calculations and criticality experiments, GE expected the reactor to go critical when loaded with 519 rods, but it actually went critical with 550 rods. GE was so sure that the calculations were correct that it began to shuffle rods around in the core and soon found that some appeared to contain less plutonium than others. Some of the rods that were not in the reactor were tested and one was found that appeared to be quite low in plutonium. GE notified the AEC.

The safeguards group at Brookhaven National Laboratory was established by the US Atomic Energy Commission (AEC) in February 1968, as the Technical support organization (TSO) for the AEC office of Safeguards and Materials Management, which was headed by

'Work performed under Contract No. DE-ACO2-76CH00016 with the U.S. Department of Energy. 
Brig. General Delmar Crowson (ret.). When it was suspected that some of the mixed-oxide rods for the SEFOR reactor did not contain the specified quantity of plutonium, General Crowson asked Tso if it could measure the rods non-destructively and estimate how much plutonium was missing.

\subsection{PRELIMINARY MEASUREMENTS}

The SEFOR reactor was designed to operate at the relatively low steady-state power of 20 megawatts or less, and to pulse to several thousand megawatts for a fraction of a second (one such transient, for example, reached a peak power of 9000 megawatts and dropped back to the steady-state value within a few milliseconds). At the low average power level, the cooling requirements were minimal. The fuel consisted of several hundred short, fat rods $(0.970$ in. in diameter and $495 / 8$ inches in overall length; see Fig. 1). The reactor was ingeniously designed so that rods could be added to, moved around in, and removed from the liquid-sodiumcooled reactor core. The whole facility was in a small building with offices, the reactor, the control room, and everything else. The manager and technical staff were from GE. The technicians were recruited from those who had experience with naval reactor operations, pleasant young men. Wes Kunkel, the health physicist, was equipped with a sodium-iodide detector and a 400-channel pulseheight analyzer. As soon as the problem was discovered, he put a sheet of plastic on the floor in his laboratory, stacked up a pile of lead bricks, and he, Lou Mansur, and others began to measure the gamma emission of the out-of-core rods through a small slit, passing each rod along in steps of about 1 inch. They used the gamma-ray line at $60 \mathrm{keV}$ from americium-241 because it gave a high counting rate. He soon found one rod that obviously contained many pellets with low plutonium content.

I doubt that we understood then what we were getting into, but, whatever it was, we had confidence that we could do it if anyone could. TSO had been operating for more than a year. Most of its members had come from Herb Kouts's critical assembly group, which had made many measurements on critical assemblies, participated in designing several interesting reactors, and had experience in measuring nuclear materials using gamma-rays and neutrons. The Brookhaven Instrumentation Division, which I had headed, had played key roles in developing sodium iodide and semiconductor detectors, and the linear amplifiers and other circuits used with the detectors.

We had visited a number of US nuclear facilities and the other major safeguards groups at Los Alamos and at General Atomics. We also knew of the work on non-destructive measurements for safeguards that Loren stieff of ACDA supported at the Naval Research Laboratory (NRL). Among other things, the NRL group conceived the idea of measuring the spontaneous fission from Pu-240 using moderated $\mathrm{BF}-3$ neutron detectors and an auto-correlation 
circuit. As I explain in the appendix on passive neutron measurements, two exactly equal time gates were needed to distinguish the fission neutrons from others that might not be proportional to the amount of plutonium in a sample. Robert chase, of the Brookhaven Instrumentation Division, designed digitized circuits for this purpose. With this supportive background, we were reasonably sure that we should be able to measure the plutonium content of the SEFOR rods, including those that had been exposed in the reactor, using high-resolution gamma-ray spectrometry and the passive neutron-detector system. In the spring of 169 we had a high-resolution germanium-detector system that we had prepared for another purpose. We asked NRL to provide the neutron detector and the Instrumentation Division to construct a portable electronics package to use with it.

Kenny Downes and I visited the SEFOR reactor on May 29, 1969. We took with us the germanium detector, a pulse-height analyzer, and a Teletype printer. The system didn't work, so we left it there, and, meanwhile, found out as much as we could about the facility and what was going on. Gene Weinstock and Sandy Wagner visited the reactor June 5. They finally got the system working and measured two cold rods and one that had been removed from the reactor to assess whether we could measure the hot rods using the high-resolution gamma-ray spectrometer. They concluded that it should be possible if the short-lived gamma-emitting fission products first were allowed to decay for a few weeks.

We requested that two rods be shipped to Brookhaven so that we could make more careful measurements. In those days such items could be sent without a lot of expensive, time-consuming paperwork. one cold and one hot rod arrived and they were carefully measured, July 11-17. These measurements reassured us that we would be able to measure the plutonium in the rods with the germanium detector and the NRL neutron detector.

I went down again to SEFOR in June 16-21 to review and analyze the measurements that GE had made with their sodium-iodide detector system and to work with them, making more measurements with it. As I explain in the appendix on gamma-ray measurements, the 60-keV gamma ray, which they had been measuring, is only indirectly related to the plutonium content and varies considerably from one batch of fuel to another. I realized that we could approximately measure the pellet-to-pellet variations using the $60-\mathrm{keV}$ gammas as they were doing, and that then we could integrate the counts for a whole rod to measure the relative intensities for a gamma-ray line at $208 \mathrm{keV}$, which is proportional to the $\mathrm{Pu}-24 \mathrm{l}$ isotope, and a region around $375 \mathrm{keV}$, which is proportional to the Pu-239 isotopic content. Since the plutonium was said to be $918 \mathrm{Pu}-239$, the 375$\mathrm{keV}$ region should give the best measure of the plutonium content of a rod. With the help of Wes Kunkel, Lou Mansur, and two engineers from the GE Vallecitos Laboratory, we recorded the counting rates for the $\mathrm{Am}-241, \mathrm{Pu}-241$, and $\mathrm{Pu}-239$ gamma rays on 60 unirradiated 
rods. Counting the earlier data taken by Kunkel, we had data on 84 rods. Only one of the rods measured so far, no. 876 , was obviously low in plutonium. At that time, 644 rods were in the reactor and 130 in the vault, of which 66 had been irradiated or were otherwise unavailable.

At the suggestion of G. Robert Keepin, six fuel rods were shipped to Los Alamos in June. His group had been formed three years earlier and was then, as now, the leading group in developing non-destructive safeguards instrumentation. Four of these rods had been removed from the reactor because they were obviously low in plutonium. One rod was from an early batch, and served as the reference. The sixth was one of the small batch with a $33 \%$ higher plutonium fraction.

The Los Alamos safeguards group measured the six rods using a lithium-drifted germanium detector to measure the Pu-239 gamma-ray at $414 \mathrm{keV}$, passive neutron emission with circuits similar to those we were using, and two neutron interrogation techniques. These measurements are described in references 1 and $2 ;$ there are profiles of the plutonium concentration in each of the rods, together with estimates of the grams plutonium in each rod.

\subsection{THE AUGUST 1969 CAMPAIGN}

We now were prepared to take measurements with the germanium detector and the passive neutron system, and we had constructed a scanner so that we could record the gamma-ray intensities along the length of the rods, rather than moving them laboriously through the Kunkel detector on the floor. The team consisted of charlie strain from NRL, to help with the neutron measurements, and Gene Weinstock, Marty Zucker, and me from Brookhaven.

The high-resolution germanium gamma-ray detectors had been developed around 1959-60, using germanium that had been highly purified for transistors. It had to be cooled by liquid nitrogen. Even then, the resolution was degraded by charge trapping at the few remaining impurities. Some genius discovered that these trapping sites could be compensated for by drifting lithium through each crystal, under an applied voltage over several days. Once this was completed, the crystals were mounted in the detector and then cooled by liquid nitrogen. They had to be maintained at this low temperature or the lithium would drift away from the impurities. Therefore, we had to transport these detectors immersed in cryostats containing liquid nitrogen with us on the airplane. They could not be checked as baggage; so, we reserved an extra seat and strapped the cryostat into it. Soon after takeoff, the cabin pressure falls and the liquid nitrogen begins to boil, sending out a visible vapor. Knowing that this would alarm some passengers, we carefully explained the phenomenon and what we were doing to the pilot and the crew before boarding the plane. They always were very helpful, explaining what was about to happen on 
the PA system as we taxied toward the runway. Some of these explanations were very colorful. Today, these detectors need to be cooled only when in use and can be checked with the baggage.

On August 11, we assembled our equipment in the SEFOR building and checked it out. GE attached a hook to a wall in a back room so that we could hang a rod on it. The high-resolution lithiumdrifted germanium detector was placed 6 feet from the middle of the rod. Each rod was measured for 50 minutes.

The NRL neutron detector consisted of two polyethylene blocks, each 9.5 inches long, 6 inches wide, and 4 inches thick. Two boron-trifluoride neutron detectors were located side by side in each block. The two blocks were separated by two one-inch-thick paraffin spacers, with a gap to push a rod through. The plutoniumcontaining section of a rod was 33.81 inches long. The system was arranged on a table so that a rod could be pushed into the detector and advanced in five steps, carefully selected to achieve nearly uniform sensitivity. Measurements were made at each location for 5 minutes. The total counts and the coincidence counts were recorded for each position.

Wes Kunkel's pile of bricks and sodium-iodide detector were moved to a work bench and placed over the rod-scanner mechanism which had been constructed at Brookhaven. We supplied a ratemeter and an Esterline Angus strip-chart recorder to plot the profile of the total counting rate. The GE pulse-height analyzer was used to record the sodium-iodide spectrum for the whole rod. Each scan took about 20 minutes plus the time to change rods, record the analyzer data, and so forth.

We worked around the clock, 24 hours a day, taking turns recording and analyzing the data and then returning to the hotel in Fayetteville for food and rest. After we had finished the measurements, we packed up our equipment and flew back home.

During this visit, we recorded data on a total of 65 rods, hot and cold, using the three instruments described above. NFS supplied data on the presumed quantity of plutonium in each rod. They had weighed each pellet stack before it was inserted into, and sealed in, a rod, assuming that the pellets contained the specified quantities of plutonium and depleted uranium. We also were given data on the plutonium and its isotopic composition in each of the 27 batches of nitrate solution produced by ARHCO, and which of these batches had been used to produce the five master blends of mixed-oxide solution. The ratio of plutonium to plutonium plus urarium in the first four blends was specified as $20.4 \%$. The ratio for the fifth blend, used to make pellets for the 18 higher enriched or "guinea-pig" rods, was specified as $27.2 \%$. The NFS data seem to have been reasonably accurate for the five master blends and the first batches. However, problems arose when scrap 
from the first pellet campaigns was dissolved and recovered as mixed oxide.

After returning home, we analyzed all of the data that we and GE had taken on 135 hot and cold rods and sent reports to the AEC, GE, and NFS. The measurements and results are described in considerable detail in reference 3 .

The results for the six rods measured at Los Alamos tended to confirm our approach, although none of them had been assayed by both of us. During 1970, we did measure them.

As I explain in the appendices, all of these passive NDA measurements depend on the isotopic composition of the plutonium and are affected by attenuation of the gamma rays in the rods, the quantity of plutonium and uranium in each rod, and other effects that require corrections. Data were corrected for all these effects, as far as we understood them at that time, and compared to the measurements made on rod number 717 , which we selected as our reference.

\subsection{THE RESPONSE TO THE FIRST REPORT}

Following our report, GE and NFS discussed the problem. GE identified certain batches of rods, rods reworked and rods produced from recovered scrap, as lacking the specified plutonium content by $5 \%$ or more, on the basis of the measurements that it had made and those made by TSO. Also, at this time, the AEC had some questions regarding the scrap that NFS had measured with some help from Kenny Downes and Anita Court of TSO.

On Dec.8, 1969, Gene Weinstock and Marty Zucker took a device to rotate 55-galion drums, a couple of NaI detectors, several neutron detectors, and the associated electronics to Erwin, Tennessee, to re-assay the waste containers. The equipment, protected by tarps, was set up just inside the gate in the fence around the NFS plant. NFS provided a small, unheated trailer where the data could be recorded and analyzed. It was cold, with rain and sleet. In 4 days, 6755 -gallon drums and eight $4 \times 4 \times 4$-foot plywood boxes were measured relative to a 13-gram sample of SEFOR mixed oxide. Twenty three of the drums had not been measured before. Fifteen drums containing solutions and raschig rings (neutron poisons) were not measurable with the equipment. The other drums and boxes were measured to check the measurements of these and others that NFS had made.

During the fall of 1969, GE analyzed the data it had taken and the data described in the TSO report of sept. 19. It concluded that the rods made from the five master blends contained approximately the correct quantity of plutonium. It also concluded that many of the rods that contained pellets made from recovered scrap and some of the original rods that had been dismantled and 
reassembled were low in plutonium. They calculated the quantities that were missing and the uncertainties for certain batches of the latter rods. GE also had dismantled some rods and had some pellets analyzed.

By this time, the AEC and the two nuclear companies wanted to have more measurements made. On April 29, 1970, GE and NFS reached an agreement on the SEFOR reactor fuel that specified the particular rod batches of concern and that "... The amount of plutonium in the fuel rods referred to in this paragraph shall be measured by Brookhaven National Laboratory according to procedures agreed to by General Electric and the Seller and with observations by the Seller's inspectors at the option of the seller."

\subsection{THE JUNE 1970 MEASUREMENTS}

During the first week in June 1970, Weinstock, Zucker, strain, and I again went to the SEFOR reactor to re-measure rods. On our previous visits, we had stayed at a hotel in Fayetteville and driven back and forth to the reactor some 20 crooked miles distant. This time, I had the good sense to ask our friends at SEFOR if they had a better idea. They suggested that we rent a cottage at the Devil's Cave state Park, about five miles from the reactor, and helped us to make the reservation. The cabins at the park had been built, and many other improvements in the park made, by the Civilian Conservation Corps during the Great Depression. Our cabin had a large, well equipped kitchen, a large living room with a fireplace, three bedrooms, a bathroom, and plenty of furniture, bedding, and household items. It was a very nice place to stay. I did most of the shopping and cooking, and the others did the dish-washing and other chores. As before, we worked around the clock, two or three taking and analyzing data while the others rested. We used the same equipment as we had in August 1969, but were better prepared to keep it operating and to use it efficiently.

By the end of this visit, we had measurements on 218 rods that we had made plus the reactivity measurements which had been made by GE. These 218 included 33 of the more credible sodium-iodide measurements, 70 high-resolution gamma-ray measurements, 80 passive neutron measurements, and 78 rods that had been measured by GE for reactivity. Also included were the six rods which had been assayed at Los Alamos in 1969. In many cases, a rod had been measured by two or three of the methods and in both 1969 and 1970 .

After all of these data had been re-analyzed and re-corrected, we reported our conclusions to the AEC, GE, and NFS.

\subsection{ADDITIONAL EXPERIMENTS AND DATA ANALYSIS}

So far, all of the measurements had been comparative ones.

The gamma-ray and neutron data all were compared to the 
measurements on rod number 717 and the reactivity measurements to rod 781. It had been suggested by us and others that a good rod should be dismantled so that the pellets could be compared to each other and, after that, two or more of the pellets destructively analyzed for plutonium content and isotopics. GE agreed to sacrifice only the bad cold rod 876. We did not realize, until the final report was being drafted, that GE had 60 kilograms of "standard" pellets. On June 25th, we observed as a technician at the GE Vallecitos Nuclear Facility opened rod 876 and removed all of the 59 pellets, one by one. Each pellet was weighed, sealed into a plastic bag and bagged out of the glovebox. After they had been removed, we made a preliminary measurement on each pellet using a NaI detector. The pellets were shipped to Brookhaven where they were transferred from the plastic bags to closely fitting plastic enclosures and sealed. In the following months, the 59 mixed-oxide pellets were carefully measured using high-resolution gamma-ray spectrometry. Then one pellet with very low and one with slightly low plutonium content were sent to the AEC's New Brunswick Laboratory (NBL) where they were dissolved. Samples of the solution were analyzed at NBL and also at Los Alamos. The NBL and Los Alamos analyses of the two pellets did not agree as to the weight percent of plutonium. Also, it was not possible, from the gamma-ray measurements on the pellets, to relate the contents of the two analyzed pellets to that of the others because the gammaray measurements of the latter showed that there were large differences in weight percent and in the isotopic composition from one to another.

As a result, the final conclusions were based on the comparative measurements, assuming that the rods chosen as references had the stated plutonium contents. There were reasons to believe that this was the case.

\subsection{THE FINAL REPORT}

By the fall of 1969, we suspected that the data which we had been given on the isotopic compositions of the five NFs master blends, and also the dates when the Pu-241 had been measured and the Am-241 had been separated out at Hanford, were faulty. After several requests, we were finally provided with the original data from Hanford on the kilograms of plutonium and isotopic assays of the 27 batches of plutonium nitrate that it had produced and measured, the dates when the Am-241 was separated out, and which of these batches were blended by NFS into its five original blends. The last of the Hanford nitrate batches was the only one in the fifth blend at NFS for the "guinea-pig" rods. The Pu-241 isotopic ratios and separation dates were very important for the $60-\mathrm{keV}$ gamma-ray measurements, and rather important for the 208-keV gammaray measurements of the $\mathrm{Pu}-241$ content. The $\mathrm{Pu}-240$ ratio was important for the neutron measurements. The $\mathrm{Pu}-240$ ratio ran from just under 8.15 to as high as $8.4 \%$. The $\mathrm{Pu}-241$ ratio ran from about 0.8 to 0.98 , when the measurements were made about 13 months apart. 
We also received a few analyses that had been made of pellets from a few of the blends by NBL. They more or less confirmed the NFS data on the $\mathrm{Pu} / \mathrm{U}$ ratios but there were small differences in the isotopic ratios.

With the new plutonium data, we had to re-analyze all of the data that we had taken and the GE criticality data to make a final report of our findings. This was contained in a letter to John Holliday, USAEC, 2111 Bancroft Way, Berkeley, CA, Aug. 19, 1971. As requested, we estimated the plutonium that was missing from certain batches identified by GE. Section 1 introduces the analysis. Section 2 compares the measurements made on rod 717 to those made on other presumably "good" rods. Rod 717 appears to be very close to the average. Section 3 presents the useful data, rod-by-rod, collected by TSO in 1969 and 1970, and the GE reactor data, mentioned above. Section 4 compares the reactivity data to the Tso gamma-ray and neutron data on 21 rods, good and bad. They match to better than one percent. Section 5 presents data on a batch of 29 rods, listed by GE, most of which were quite low in plutonium. We concluded that the deficit for these was about 3.4 $\mathrm{kg}$. In section 6 , we conclude that about $0.85 \mathrm{~kg}$ of $\mathrm{Pu}$ is missing from the rods in batch 625. Section 7 says that about 345 grams are missing from the rods re-worked after 8/18/68. The final conclusion, in section 8, is that the total deficit is $4.60 \pm 0.46$ $\mathrm{kg}$ of plutonium out of the $433 \mathrm{~kg}$ expected. The uncertainties assigned are explained. The conclusions are based on the assumption that the reference rods contained the specified quantities of plutonium.

GE, NFS, and the AEC accepted this conclusion. After the June 1970 excursion to SEFOR, TSO was requested to provide a rod scanner to NFS for the additional rods that it was to make for GE. This scanner and detector system was intended only to detect low or high pellets, not to provide an NDA measurement of the content of the rods. TSo also was requested to comment on some NFS estimates of the plutonium content in several waste containers, and we were invited to visit the Erwin plant while it was being decommissioned and scrap and waste were finally being measured. When the whole operation was completed, the plutonium unaccounted for (MUF) was comparable to the propagated uncertainties for the plutonium produced at Hanford and for the plutonium in the rods and in the scrap and wastes recovered by NFS.

\subsection{CONCLUSIONS}

Those of us who participated in this exercise did what was expected of us, in spite of all of the problems that we faced. We learned a great deal that was to be useful to us in the future. An important lesson was that it is essential to have well qualified and representative reference materials to draw absolute conclusions, so that it is not necessary to rely entirely on relative measurements. Largely as a result of the SEFOR experience 
in 1969, General Crowson proposed, and the AEC authorized, a oneyear program to introduce the private nuclear facilities that were processing plutonium or high-enriched uranium to non-destructive assay instruments. Brookhaven was chosen to oversee the project. A number of such companies were invited to submit proposals and to share the costs. Six contracts were negotiated in January, 1970. Two were for assay of high-enriched uranium, one using a neutron interrogation technique developed at Los Alamos, and one using an isotopic neutron source developed by General Atomics Radiation Technology. Four were for the assay of mixed plutonium-uranium fuels, using high-resolution gamma-ray spectroscopy and neutronwell counters developed from the NRL prototype. One of the latter was with the GE Vallecitos Nuclear Facility, where rod number 876 was dismantled. GE was able to carry out a fully measured material balance for a small campaign to fabricate mixed-oxide (MOX) fuel rods for testing in a commercial nuclear power reactor. In addition to the customary chemical analysis of samples, the plutonium received was verified using a calorimeter, each rod was scanned using a germanium detector, and all scrap and waste was measured using a passive neutron-well counter. Appropriate reference standards were fabricated by GE. A by-product of this experiment was that we learned about the high-resolution gamma-ray systems that Ray Gunnink had developed at Livermore. Gunnink went on to develop the gamma-ray spectrometry technique that is now widely used to measure the isotopic ratios of plutonium and americium. If it had been available in 1970, it would have saved us a great deal of trouble. 


\subsection{ACKNOWLEDGMENTS}

My other three colleagues who took and analyzed the data at the SEFOR reactor contributed at least as much as $I$ did to accomplishing our mission and to the pleasure of working together. Marty zucker and Gene Weinstock had the least fun when measuring the waste containers at Erwin, Tennessee, out of doors in the middle of winter. Charlie strain's analysis of the neutron instrument and of the data taken with it was extremely important. I have sought in vain to locate Charlie strain through the Naval Research Laboratory, from which he and his colleagues have long since gone.

After writing this paper, I sent a copy to Jim Tape at Los Alamos requesting advice as to what $I$ should do with it. He and Darryl Smith suggested that it be issued as a Brookhaven report and that someone should write a summary of it for the INMM Journal. Darryl smith did much more than this. He read every word and made editorial and technical suggestions on every page. He suggested better references and corrected my misconceptions. I am much in his debt.

As our colleagues at Los Alamos suggested, Brookhaven National Laboratory agreed to publish this as a historical report. Gene (Eugene V.) Weinstock laboriously converted our draft from my obscure word-processor language to wordPerfect so that his disk could be used by the printer, wrote the description of what the SEFOR experiment accomplished, clarified the draft in many places and, with the valuable help of the TSo librarian, Kathy Lancaster, located more of the important references. He should have been a co-author; the only reason for my being the sole author is that it was my idea that this experience should be written up, and that I composed the first draft. Avril woodhead, the Brookhaven senior reviewer, read the manuscript carefully and made a number of thoughtful and constructive suggestions. My heartfelt thanks to all those who have been so helpful. 


\subsection{APPENDICES}

\section{A. 1: The SEFOR REACTOR EXPERIMENT:}

The SEFOR reactor was designed to measure the sign and the magnitude of the Doppler effect in a sodium-cooled fast reactor. The Doppler effect refers to the broadening of the neutron capture resonances in the $\mathrm{U}-238$ as the fuel heats up. Broadening reduces the peak cross sections in the neutron capture resonances and therefore the self-shielding of the fuel against penetration by resonance-energy neutrons. Broadening is caused by the distribution of the thermal velocities of the capturing nuclei relative to the incoming neutrons (there is, first of all, the distribution of the thermal speeds of the nuclei and, second, the distribution of directions of movement relative to the neutron velocity vector, both of which enter into the calculation of the Doppler effect). As a result of the broadening, the interior of the fuel is more exposed to and, therefore, more effective in capturing neutrons near the resonance energies. These resonance captures are parasitic, i.e, they do not produce more neutrons but, instead, absorb them. The overall effect is a reduction in the number of neutrons available to carry on the chain reaction. Consequently, the reactivity of the reactor drops as the fuel heats up, a very important safety feature. Until the experiment was performed it was not empirically established that the theory was correct, nor was the magnitude of the effect known.

The reactor was operated at a relatively low power level, a few megawatts, then a boron-carbide piston was shot out of the core at high speed, putting the reactor in a super-prompt critical state. In a short time, the power surged to around 10,000 megawatts. Through the Doppler effect, the resultant heating of the fuel shut the reactor down almost instantaneously (the actual duration of the power spike was just a few milliseconds).

The SEFOR reactor experiment is described in references 4-7.

A. 2: THE ORIGINAL ORDER:

The original order by GE was for:

756 "standard" rods with $20.4 \%$ plutonium/uranium-plusplutonium

18 "guinea-pig" rods with $27.2 \% \mathrm{Pu} / \mathrm{Pu}+\mathrm{U}$ rods.

$60 \mathrm{~kg}$ of "standard" pellets, and an option to buy 50 more

The plutonium was to be $91.3 \%$ fissile.

The uranium was to be $0.22 \% \pm 0.01 \% \mathrm{U}-235$ by weight.

The plutonium was prepared as plutonium-nitrate solution by the Atlantic Richfield Hanford Company between Nov. 1965 and Dec. 1966 in 27 batches, containing from about 4 to $26 \mathrm{~kg} \mathrm{Pu}$ each. This 
nitrate solution then was loaded into 10-liter polyethylene bottles and shipped to NFS. NFS blended the plutonium-nitrate solution with depleted uranium-nitrate solution to make five master blends, four for the standard rods and one for the guinea-pig rods. Each plutonium-nitrate solution batch was analyzed by ISOCHEM (later taken over by ARHCO) for grams per liter of plutonium and for the plutonium isotopic ratios. The total quantity of plutonium in all solutions was given as $545 \mathrm{~kg}$. NFS used the Hanford data on grams per liter and isotopics, and its own data on the depleted uranium nitrate solution. I believe that the first five blends were sampled and the samples measured to confirm that the blends met the specifications. Evidently, NFS assumed that the dissolved scrap would have the same composition. The numbers of rods and the batches that were low in $\mathrm{Pu}$ were described in our final report above.

The SEFOR rods were unusual (see Fig. 1, from Reference 7.) Their overall length was 49 and 5/8th inches. There was a hook at the top which was used to lift the rods into and out of the reactor and to move them around inside. It also was used to hang the rods in the vault and to hang them vertically on a wall in the shippingreceiving area for the germanium gamma-ray measurements. The bottom end was pointed. The fuel was in two sections with a gap of 2 inches between them. The top section was 13 and $3 / 16$, and the bottom section was 26 and $5 / 8$ inches long. In each of the two sections, the top and bottom-most pellets had no plutonium. These "insulator" pellets contained only depleted uranium oxide. obviously, some of these pellets had been mixed in with the plutonium-bearing pellets when the scrap was re-dissolved for use in the later batches of rods.

\section{A.3: PROGRESS IN NDA INSTRUMENTATION:}

As noted in the text, the germanium detectors available in 1969-70 were compensated by drifting lithium through each detector crystal. The AEC supported the research of Robert Hall at GE, schenectady, for about ten years, ultimately demonstrating (1974) how ultra-pure crystals could be grown for gamma-ray detectors (see References 8 and 9 for accounts of Hall's important contributions.) As noted, these need to be cooled to the temperatures of Iiquid nitrogen only while in use. They have become an essential instrument for the IAEA. Brookhaven and Los Alamos constructed larger moderated neutron detectors and improved the autocorrelation circuits. Klaus Böhnel (References 10 and 11) suggested the shift-register circuit when he was working with the safeguards group at Los Alamos. Jim Swanson should get the credit for designing and constructing the first one. This circuit is a great improvement over the two-gate circuits developed by NRL and Brookhaven. With these, a new gate could not be started before the previous one had ended, which caused large deadtime losses for most useful samples. In addition, the shift-register circuit counts multiple pulses as they should be counted theoretically. Great 
improvements have been made in these systems and the special techniques needed to assay larger samples, which have high counting rates, significant detector deadtime losses, and selfmultiplication. Similar instruments have been developed to measure the fissile isotope in uranium samples (which has essentially no spontaneous fissions) by irradiating them with neutrons from an isotopic neutron source.

In the conclusion, I mentioned the development by Ray Gunnink of the high-resolution gamma-ray instruments to measure the plutonium isotopic ratios and the Am-241 in plutonium metals, oxides, and solutions. He and Los Alamos and others have developed additional gamma-ray techniques for a variety of other safeguards applications.

Modern methods for recording and analyzing data are a great help. Our neutron data was read out from the electronic counters and recorded by hand. The data from the multichannel analyzer with the GE sodium-iodide detector was printed out with an electric typewriter and had to be copied and added up later. Our germaniumdetector data was printed out and punched on paper tape by a teletype machine. For computer analysis, the latter had to be copied onto magnetic tape. Such analysis now can be done on computer chips included in the electronics package, and the computer can be programmed to perform most of the analysis we did manually. We invested a lot of time and effort copying, reducing, correcting, and analyzing the data. To have been able to do so on the spot would have been a great help.

Reference 12 describes gamma-ray spectrometry and passive neutron techniques and instruments in considerable detail. This volume was prepared by personnel at Los Alamos for the office of Nuclear Regulatory Research, US Nuclear Regulatory Commission. Also, Reference 13 has a succinct review of both passive and active techniques.

\section{A. 4: GAMMA-RAY MEASUREMENTS:}

In these appendices, I assume that the reader knows something about the gamma-ray and neutron parameters of the isotopes that we measured. The plutonium was about $91 \% \mathrm{Pu}-239,8 \% \mathrm{pu}-240$, and less than 1\% Pu-241. There was no measurable $\mathrm{Pu}-238$ and very little Pu-242. Pu-239 has a half life of 24,000 years, Pu-240 of 6,570 years, and Pu-241 of 14.75 years. The latter decays by beta emission to Am-241 with a half-life of 432 years. A very small fraction of the time $\mathrm{Pu}-241$ decays to $\mathrm{U}-237$, which decays with a half-life of 6.75 days to $\mathrm{Np}-237$, emitting a 208-keV gamma ray. The disintegrations per second are inversely related to the halflives. The Pu-241 decays at almost 5\% per year. The quantity of Am-24I is a function of the quantity of Pu-241 and of the time since Am-241 was last removed from the material. The "branching 
ratio," the fraction of the time that a disintegration is accompanied by a gamma ray, ranges from 1 to less than one in $10^{10}$.

All of the gamma rays may be scattered or captured by atoms in the material being assayed, especially by the uranium and plutonium. The pellets had a specific gravity of about 10 and the $\mathrm{Pu}+\mathrm{U}$ weight fraction was about 0.88 . Consequently, the gammas emitted at full energy from a pellet come, in effect, from a layer near the surface. For $60 \mathrm{keV}$, this is about $0.016 \mathrm{~cm}$, and there is additional attenuation by the cladding and the detector's housing. For $208 \mathrm{keV}$, the effective layer is about $0.11 \mathrm{~cm}$., and for $414 \mathrm{keV}$ it is about $0.44 \mathrm{~cm}$. That the Am-241 measurements were as consistent as they were attests to the high uniformity of the blends and of the rods' cladding.

Although the quantity of Am-241 was very small and varied from batch to batch, its branching ratio is about unity, which is why its $60-\mathrm{keV}$ gamma ray was attractive for measuring the pellet-topellet variation in the rods. Another reason is that it is easily distinguishable with a sodium-iodide, low-resolution detector. The 208-keV gamma ray from the decay of U-237 to $\mathrm{Np}-237$ also has a relatively high branching ratio. Since our neutron measurements relied on the isotopic data that we were given, we felt it necessary to determine if the $\mathrm{Pu}-241$ and $\mathrm{Am}-241$ we measured confirmed that data. Today, a few careful gamma-ray measurements would provide this information for any batch or rod or pellet in a few hours. Our objective was to verify the information given us some of which, as noted above, turned out to have been in error.

The resolution achievable by sodium-iodide scintillation and intrinsic germanium detectors is widely published. It was obvious that the sodium-iodide system could not distinguish the Pu-239 gammas from those from the many shorter-lived fission products in the rods which had been irradiated. As soon as Gene Weinstock and Sandy Wagner had made the first measurements, it was clear that the high-resolution gamma-ray system should work after the shorterlived fission products had been allowed to decay.

It seemed to be fast and easy to make rough profile measurements of the rods using the sodium-iodide detector and some of the more intense, though not truly representative, gamma rays. This was an easy way to spot the rods with pellets of very different plutonium content. It even worked for the irradiated rods, because the burnup was higher where the more plutonium-rich pellets were.

\section{A.5: THE NEUTRON MEASUREMENTS:}

It seemed to be important to us to use two different nondestructive methods of measurement to ensure that some factor which we might overlook did not bias our results. The gamma-ray and neutron instruments are quite different, and they respond to 
different isotopes of plutonium. Neutrons are not significantly absorbed in the rods, so that they are proportional to the quantity of plutonium. The gammas are strongly absorbed, as noted above. If the plutonium is not distributed uniformly throughout a pellet, the gamma measurements give a wrong result.

The so-called neutron-coincidence circuit has been described in many books and reports, and has been considerably improved since it was first proposed by Jacques Jacquesson (ref. 14). As I describe in the article, the detector that we had was small, so that we had to measure five sections of each rod. The idea is to measure the fissions from the spontaneous fission of the even plutonium isotopes, $\mathrm{Pu}-240$ in our case. Plutonium samples may also produce neutrons by the $(\alpha, n)$ reaction of the alpha particles emitted by the plutonium with isotopes of lighter elements in the sample. As Charlie strain knew, an isotope of oxygen in this fuel would produce some unknown quantity of $(\alpha, n)$ neutrons. It was to distinguish the multiple spontaneous-fission neutrons from the single neutrons due to $(\alpha, n)$ or other reactions that Jacquesson invented the auto-correlation technique to use with thermalized, and efficient, neutron detectors. In our case, the raw, or total, counting rates were exactly proportional to those from the coincidence circuit, due only to fissions. As a result, we used both results to check on each other and to reduce the statistical uncertainty associated with small counting rates.

Another possible problem is self-multiplication. The neutrons from spontaneous fission may induce fissions in the fissile isotopes, Pu-239 in our case. When this occurs, the total counting rate is increased and the coincidence counting rate is increased more rapidly. Strain checked this two ways. He checked that the ratio of the total counting rate to the coincidence rate remained the same, and also checked that the ratio for the more enriched guinea-pig rods to the standard rods was exactly what it was supposed to be. Both checks confirmed our assumption that there was no significant self-multiplication for these rods with our system.

To be accurate, it was necessary to confirm the data on the Pu-240 isotopic ratios, which varied by about $1.5 \%$. from batch to batch. Although this was not very important, we corrected for it and ensured that the neutron data were consistent with the others.

The specification required that the content of each rod should be within $\pm 2 \%$ of the median value. Since it is difficult to make pellets of exactly the same weight, the rod contents varied by one percent or so from the mean. As noted in the article, NFS carefully weighed each rod load before it was stuffed into a rod. We used this data, which appeared to be quite accurate. 


\section{A. 6: CRITICALITY MEASUREMENTS}

As I mentioned at the beginning, General Electric's scientists were able to predict almost exactly how many fuel rods would be required to achieve criticality. Their comparative measurements of the fissile content of the rods, by shifting them around within the core, were at least as sensitive and as accurate as any non-destructive measurement is likely to be. sub-critical assemblies have been used for this purpose to good effect. The reactivity as measured in a fast critical assembly or reactor is primarily proportional to the fissile isotopes, in this case, Pu-239 and a small quantity of Pu-241. The fissile ratio was about $91 \%$ and almost the same for all of the batches. The method may be more sensitive to the fissile content in the center than at the ends of a rod, because neutrons leak out of the surface of the core and the fission rate is smaller there.

When all of the different measurement results are compared, the reactivity values appear to be as reliable as the combination of gamma-ray spectrometry and passive neutron assays. 


\subsection{REFERENCES}

1. LA-4315-MS, Program status Report of the Nuclear Safeguards and Development Program, July-sept. 1969, Los Alamos National Laboratory, Los Alamos, NM.

2. WASH-1147, proceedings of the AEC Symposium on Safeguards Research and Development, Oct. 27-29, 1969, US Atomic Energy Commission, pp. 116-120.

3. Gamma and Neutron Measurements of SEFOR Rods, Technical Support organization report for the USAEC Office of-Safeguards and Materials Management, Brookhaven National Laboratory, Sept. 19, 1969.

4. B. Wolfe, The SEFOR Project -- Its Significance and Progress, Proceedings of the American Power Conference, Vol. XXIX, pp. 189-201, Illinois Institute of Technology, Technology Center, Chicago, Ill. 1967 .

5. K.M. Broom and S.L. Mitchell, SEFOR: Southwest Experimental Fast oxide Reactor, Proceedings of a symposium on Progress in Sodium-Cooled Fast Reactor Engineering held by the International Atomic Energy Agency in Monaco, 23-27 March 1970, pp. 33-40, IAEA, Vienna, 1970.

6. GEAP-5576, Final Specifications for the SEFOR Experimental Program, L.D. Noble and C.D. Wilkinson, AEC Research and Development Report, January 1968.

7. G. Billuris et al, SEFOR Plant Design, pp. 5-10 to 5-30, in proceedings of the Fast Reactor Topical National Meeting, American Nuclear Society (Northern California section), San Francisco, CA, April 10-12, 1967.

8. R.N. Hall and T.J. Saltys, High Purity Germanium for Detector Fabrication, IEEE Trans. Nuclear Science, Vol. 18, No. 1, p.160, 1971.

9. R.N. Hall, Chemical Impurities and Lattice Defects in High purity Germanium, IEEE Trans. Nuclear Science, Vol. 21, No. 1, p.260, 1974 .

10. K. Böhnel, Two New Instruments for Nondestructive Assay with Neutrons, Trans. Am. Nucl. Soc., 1972 Winter Meetings, Nov. 12-17, 1972, pp. 671-72.

11. K. Böhnel, Determination of Plutonium in Nuclear Fuels Using the Neutron Coincidence Method, KFK-2203, AWRE Translation No. 70 (54/4252), Kernforschungszentrum Karlsruhe, March 1978. 
12. D. Reilly, et al, Passive Nondestructive Assay of Nuclear Materials, prepared for the U.S. Nuclear Regulatory Commission and available from the superintendent of Documents, U.S. Government Printing office, Wash. D.C., as NUREG/CR-5550, March 1991.

13. R. Sher and S. Untermeyer II, The Detection of Fissionable Materials by Nondestructive Means, a monograph published by the American Nuclear Society, 1980.

14. J. Jacquesson, Enumeration of Nuclear Processes Involving the Simultaneous Emission of Several Neutrons, J. Phys. 24, Supplement to No. 6, 112A-16A, -1963. 


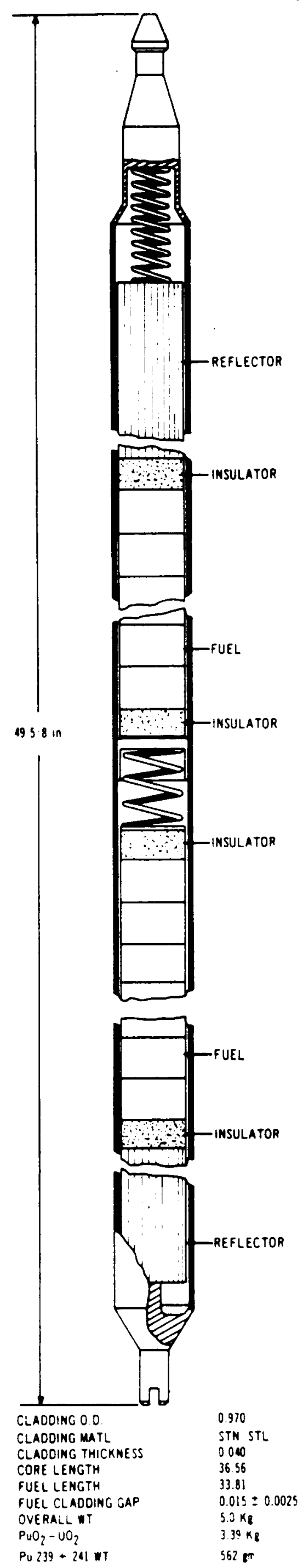

Figure 1. Euel Rod (from Ref. 7) 